\title{
Theoretical accounts of Gulf War Syndrome: From environmental toxins to psychoneuroimmunology and neurodegeneration
}

\author{
Eamonn Ferguson and Helen J. Cassaday \\ School of Psychology, University of Nottingham, Nottingham, NG7 2RD, UK \\ Tel.: +44 1159 515327; Fax: +44 1159 515324; E-mail: eamonn.ferguson@nottingham.ac.uk; \\ helen.cassaday@nottingham.ac.uk
}

\begin{abstract}
Non-specific illness includes a wide variety of symptoms: behavioural (e.g., reduced food and water intake), cognitive (e.g., memory and concentration problems) and physiological (e.g., fever). This paper reviews evidence suggesting that such symptoms can be explained more parsimoniously as a single symptom cluster than as a set of separate illnesses such as Gulf War Syndrome (GWS) and chronic fatigue syndrome (CFS). This superordinate syndrome could have its biological basis in the activity of pro-inflammatory cytokines (in particular interleukin-1: IL-1), that give rise to what has become known as the 'sickness response'. It is further argued that the persistence of non-specific illness in chronic conditions like GWS may be (in part) attributable to a bio-associative mechanism (Ferguson and Cassaday, 1999). In the case of GWS, physiological challenges could have produced a non-specific sickness response that became associated with smells (e.g., petrol), coincidentally experienced in the Persian Gulf. On returning to the home environment, these same smells would act as associative triggers for the maintenance of (conditioned) sickness responses. Such associative mechanisms could be mediated through the hypothalamus and limbic system via vagal nerve innervation and would provide an explanation for the persistence of a set of symptoms (e.g., fever) that should normally be short lived and self-limiting. We also present evidence that the pattern of symptoms produced by the pro-inflammatory cytokines reflects a shift in immune system functioning towards a (T-helper-1) Th1 profile. This position contrasts with other immunological accounts of GWS that suggest that the immune system demonstrates a shift to a Th2 (allergy) profile. Evidence pertaining to these two contrasting positions is reviewed.
\end{abstract}

Keywords: Cytokines, interleukin-1, stress, Gulf War Syndrome, Pavlovian conditioning, neurodegeneration

\section{Introduction}

There is now a range of evidence to suggest that as well as physiological challenges and trauma both psychological parameters and environmental factors have an important role to play in the presentation and severity of disease [9]. These effects are not limited to self-reports of symptoms and illness but also include changes in physiological parameters $[60,101]$. Such interactions are plausible because sensory information can influence physiological parameters (e.g., immune cell trafficking or reactivity) via neurological media- tion. This can be either central via limbic system structures or more direct via brainstem structures (see [69, 70]). Research has tended to focus on these mechanisms more in relation to established conditions, such as cancer [3], viral recurrence [57], the common cold [15] and physiological mechanisms such as wound healing [59], rather than in conditions where the diagnostic criteria are less well established (cf. $[8,105])$. The spectrum of symptoms reported in the latter conditions is often referred to as functional or medically unexplained $[8,18]$. In this review we examine, and attempt to integrate, the different theoretical perspec- 
tives taken on one such condition: Gulf War Syndrome (GWS). Recent theory and empirical evidence suggests that medically unexplained symptoms (MUSs) may be accounted for by a single symptom dimension. If so, in addition to an improved understanding of GWS in and of itself, the theoretical analysis presented should give insights into other conditions (e.g., chronic fatigue syndrome, irritable bowel syndrome). Given the diversity of theoretical perspectives taken on GWS we shall summarize the strengths and weakness of each and then present a theoretical synthesis in terms of a psychoneuroimmunological account.

The spectrum of symptoms observed in GWS is broad and diverse involving cognitive (e.g., memory), behavioural (e.g., anorexia), emotional (e.g., anxiety) and physiological symptoms (e.g., fever). Thus a complete theoretical account of this diversity will inevitably involve interactions between neurological, immunological and behavioural processes. The main body of this paper is structured around theoretical accounts of GWS based on separate neurological, psychological, behavioural, immunological and psychiatric mechanisms. These separate theoretical accounts are evaluated against two main criteria: (1) their ability to account for the symptom diversity and (2) their ability to account for the persistence of symptoms. Then an integrated perspective based on psychoneuroimmunology is presented.

While there is some debate as to whether the term syndrome is applicable to the array of symptoms reported by Persian Gulf War veterans, the term Gulf War Syndrome (GWS) is used in this paper for consistency with most published studies. Before exploring the different theoretical accounts, this review will first address the nature of the illness experienced on return from the Persian Gulf.

\section{GWS - does it exist?}

Like other multi-system syndromes (e.g., chronic fatigue syndrome, CFS), GWS is a controversial disorder. In part, the controversy surrounding these disorders arises because the breadth of reported symptoms makes both differential diagnosis and the identification of aetiologic agents problematic (see [16]). With respect to GWS it has been argued that the pattern of symptom clusters seen in veterans is qualitatively similar to the pattern reported by healthy era controls (e.g. [21,52, 61]) and that no clear diagnosis can be made from the clinical reports (see [53]). In this case, there would be nothing unique about GWS (but see e.g. [96]).

This is based on the idea that illness is best viewed categorically; however, it is equally valid to view illness dimensionally (cf. [120]). In the case of GWS, this would mean that the same underlying biological processes could result in symptoms in healthy controls (with a similar pattern but expressed at a lower level). Consistent with this, all published papers on GWS have demonstrated that veteran groups report higher levels of symptoms than controls (including era veterans) (e.g. [51,85,109,113]). There is also evidence to suggest that patients with different psychiatric diagnoses produce similar patterns of symptom clusters in response to diagnostic symptom assessments [111, 112]. However, it does not necessarily follow that clusters of symptoms that are similar share the same underlying causal mechanism [28]. For example, colds and flu show similar patterns of symptoms, but their causal agents are different, although, in this case, aspects of the biological mechanisms (immune system activation) are similar.

The second argument to suggest that GWS does not exist is based on the similarity of post-war death rates, hospitalization, birth defects and suicide rates in veterans and controls $[36,67]$. However, it has been argued that these results may reflect a number of methodological and statistical biases [39]. One such bias is the 'healthy warrior effect', or the notion that deployed troops are going to be healthier (physically and mentally) than non-deployed troops. If this were the case, then it would be expected (other things being equal) that the non-deployed troops would be more likely to present with illness than the deployed 'healthier' group (discounting the effects of their war zone experiences). If this potential bias is acknowledged, it follows that no difference between the comparison groups (deployed versus non-deployed) would mean that the deployed 'healthier' groups were nevertheless more ill (but see [17,35,37,40,56]).

Finally it has been argued that the spectrum of symptoms documented in GWS is similar to that seen in other wars (e.g., [49,105]). However, Haley [38] argues that: (1) the conditions present in other wars (e.g., the American Civil War) were fundamentally different to those in the Persian Gulf; (2) the diagnostic tests for the physical causes of illness were not as developed as they are today; and (3) for certain wars (i.e., the Vietnam War) assessments took place a long time after the cessation of hostilities. Thus it has been suggested that the post-war syndromes seen after other conflicts are not comparable [38]. 
In sum, Gulf War veterans report increased levels of symptoms that have persisted for 10 years. While there is not sufficient evidence to state that there is a unique 'syndrome' (cf. [118]), the extent of distress suffered by these veterans is just cause to try and explain their condition. With an improved understanding of the mechanisms associated with GWS, we will be in a position to begin to understand the similarities and differences between GWS and other functional syndromes such as chronic fatigue syndrome (CFS).

\subsection{GWS and other functional somatic syndromes}

GWS shares many symptomatic features with other functional somatic conditions (e.g., chronic fatigue syndrome [CFS] or irritable bowel syndrome [IBS]) and as such any theoretical account that can offer a reasonable explanation for GWS should also be considered as a potential candidate explanation for these conditions (cf. [8]). For example, both factor analytic [18] and theoretical work $[8,120]$ examining the co-morbidity of a variety of functional syndromes such as CFS and IBS has suggested that these can be explained by a single higher order factor (see also [29]). This is consistent with the possibility of a shared bio-psychosocial mechanism [8]. Figure 1 provides a schematic representation of the link between the factors identified by Haley et al. [43] for GWS and Deary's [18] analysis of other functional syndromes.

In addition to specifying the underlying dimensions in different functional syndromes, there is also a need to understand temporal variability. For many chronic conditions patients will report that they have good days and bad days. Is there similar temporal variability in GWS? Most studies examining the breadth of symptoms associated with GWS have tended to make single time interval assessments, so, at present, virtually nothing is known about the temporal patterning of symptoms in GWS. One study measured the symptoms of GWS at two time points separated by 2-4 years [86], finding no significant changes in the level of reported symptoms. By contrast, other research, exploring 'anniversary reactions' in veterans, has demonstrated systematic variability in subjective health states: following their return from the Gulf, veterans report more severe symptoms during the same months that they experienced their most traumatic experience in the Gulf [79]. This is consistent with the position that symptoms associated with GWS show temporal variation associated with wartime triggers/events. However, the temporal resolution of this work is broad and day-to-day variability has yet to be explored [29].

\subsection{Criteria for an adequate account of GWS and other (MUSs)}

The following criteria are proposed for evaluating theoretical explanations of GWS. First and foremost, a complete account should be able to account for the breadth, persistence and variability of the symptoms. If an account of GWS can explain the breadth, persistence and variability in symptoms then the following additional criteria should also be applied to judging the plausibility of that account: (1) the proposed account should suggest testable hypotheses, (2) it should relate experiences in the Gulf to the veterans' current symptoms, and (3) a full explanation should include a biological mediating pathway for the symptoms experienced.

\subsection{Theoretical explanations of GWS}

Five accounts of GWS are described below and grouped in terms of their proposed mechanisms of operation: (1) psychological, (2) neurological, (3) immunological, (4) behavioural and (5) psychoneuroimmunological. Of course they are not mutually exclusive. For example, stress (psychological) is used to explain how conditions in the Gulf may have assisted in allowing organophosphates (OPs) to enter the central nervous system (CNS) (but see [103]). However, in this case OP poisoning is the immediate cause of the neurological damage seen in GWS, not stress per se $[38,41]$.

\section{Psychological mechanisms}

A range of psychological accounts of GWS (e.g., stress, post-traumatic stress disorder and psychiatric co-morbidity) are reviewed below.

\subsection{Stress}

There is already good evidence that the experience of stress is related to a variety of physical health parameters. Psychological stress activates the hypothalamic-pituitary-adrenal (HPA) and sympathetic-adreno-medullary (SAM) axes. It is argued that the subsequent release of corticosteroids influences disease states (see [26]). Again in such cases, stress is not necessarily causal as such, but (though the evidence on this is mixed) stress may act to moderate biological systems (e.g., the blood-brain-barrier) 


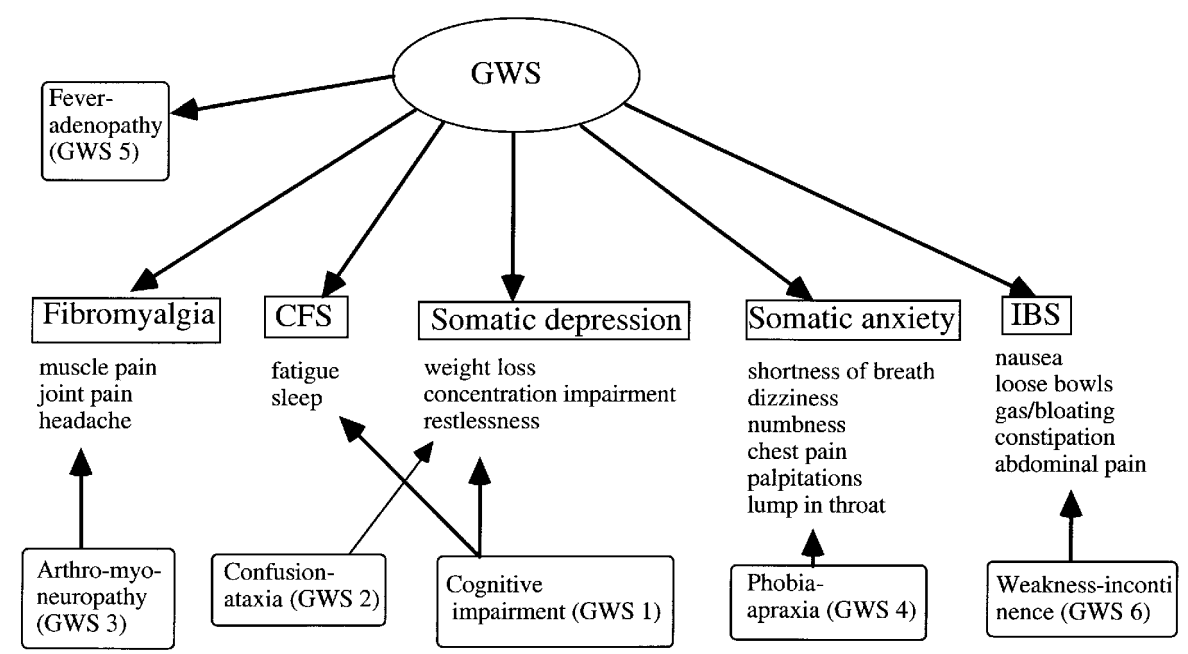

Note: GWS1, 2, 3, 4, 5 \& 6 refer to IIaley et al.'s (1997 [43]) syndromes. Fibromyalgia, CFS, Somatic depression, Somatic anxiety and IBS from Deary (1999 [18])

Fig. 1. GWS: single or multi-faceted syndrome?

to make them more susceptible to disease provoking agents [45]. However, effects on the permeability of the blood-brain-barrier have not been consistently reproducible [103].

There are a number of papers that have explored the role of the self-reported levels of battlefield stress in relation to levels of currently reported symptoms of GWS. Some suggest that self-reports of battlefield stress have limited explanatory power (see [109]), providing, for example, little account of the diversity of symptoms [86]. However, others have demonstrated that, compared to healthy controls, veterans with CFS and psychiatric co-morbidity report more stressful events 6 months after the war [31]. These authors further find that veterans with CFS or with CFS and multiple chemical sensitivity (MCS) do in fact report more combat stress exposures (though in this case there was no control for psychiatric co-morbidity). It has also been demonstrated that reports of exposure to particular battlefield stressors (e.g., the belief that biological or chemical weapons were used, cf. [30]) were associated with reports of current symptom levels [80].

The evidence reviewed above suggests that battlefield stress cannot provide a complete account of current illness. However, there are a number of issues that need to be considered before its role is dismissed altogether. First, stress experienced during environmental exposures in the Gulf could have made biological systems more vulnerable to disease provoking agents [45] (but see [103]) and any such interactive effects would not be detectable (only) through the retrospective re- call of (moderating) events. Second, through hormonal modulation, chronic stress can affect the function of the HPA axis as well as neurological structures. For example, in a rat model it is possible to examine the effects of blocking corticosteroid action in the hippocampus, compared with the more widespread effects produced by intracerebroventricular injection of selective antagonists. There is data to suggest that these endogenous steroid hormones are homeostatically regulated (with circadian fluctuation) by both hippocampal and extrahippocampal corticosteroid receptors [14]. Additionally it has been found that fluctuations in corticosterones can produce neurotransmitter disturbances, for example in hippocampal 5-HT receptor function, consistent with the effects of chronic stress in producing depression [76].

Stress and stress related hormones have also been demonstrated to affect cognitive functions dependent on the hippocampus. For example, experimentally, both chronic psychosocial stress (in subordinate tree shrews) and long-term cortisol treatment affect memory processes that rely on normal hippocampal functioning [81]. The hole board paradigm was used to provide a tests of spatial reference memory (known to be sensitive to the effects of hippocampal lesions, see e.g. [107]). These impairments were furthermore associated with a tendency towards reduced hippocampal volume, as measured by MRI, consistent with the finding that stress and glucocorticoids can cause structural changes in hippocampus [74]. 
In human subjects, stress has similarly been found to affect cognitive processes. For example, a naturalistic study using examination stress in students found that changes in (salivary) cortisol during exam times were correlated with increases in the perceived level of stress and some impairment in attention and (shortterm) memory [115]. Thus stress can have interactive neuropsychological effects (see also section on $\mathrm{Neu}$ rological mechanisms below). However, on its own, stress is not sufficient account of the breadth, persistence and temporal variability of symptoms seen in GWS.

Thus while the role of stress may be limited it can operate synergistically with other vulnerability factors to produce symptoms.

\subsection{Post traumatic stress disorder (PTSD)}

The effects of the long-term chronic stress experienced by veterans could be especially serious in those with a diagnosis of PTSD. There are essentially two arguments pertaining to PTSD and GWS. The first concerns the differential prevalence rates of PTSD in Gulf War veterans compared to controls. The second concerns whether or not the levels of symptoms reported by Gulf War veterans can be accounted for by variation in levels of PTSD.

With regard to the first issue a number of studies have reported a higher prevalence of PTSD in Gulf War veterans than in controls (e.g. [7,72]). However, it has been argued that this higher prevalence of PTSD represents a false positive error rate due to the relative sensitivities and specificities of the assessments used for the diagnosis of PTSD [38].

A number of studies have shown that PTSD is related to the reporting of current physical symptoms of GWS (see [7,25,122]). The strength of this relationship is not large enough to support the view that PTSD provides a complete account of GWS. However, even given Haley's [38] critique of the assessment of PTSD in veterans, the consistency in the results in relation to symptom reporting suggests that some PTSD-related mechanism contributes to GWS (see [50]).

\subsection{Psychiatric co-morbidity}

Can the physical symptoms reported in GWS be explained by psychiatric co-morbidity in veterans? A number of studies have examined these issues using a variety of diagnostic tools (see [62,108]). A number of authors writing recently agree that psychiatric diag- nosis and co-morbidity, while apparent and important (e.g., increased levels of depression and PTSD), do not reflect a major cause of the physical symptoms reported in GWS [62,121].

\subsection{Summary of psychological mechanisms}

Three psychological mechanisms have been discussed (stress, PTSD and psychiatric co-morbidity). It is concluded that battlefield stress may have acted to make veterans more susceptible to OP poisoning (but see [103]). Chronic stress (maybe manifest in PTSD) might even have led to neuropsychological changes. Thus stress needs to be considered in models of GWS, but as a moderating factor rather than as sufficient cause in itself. Neither levels of stress, PTSD, nor psychiatric co-morbidity, can account for the breath of symptoms seen in GWS, or for their persistence. However, PTSD may account for some degree of temporal variability (e.g., anniversary reactions).

\section{Neurological mechanisms}

A number of hypotheses focus on neurological damage. These suggest that environmental toxins produce alterations in the CNS that can result in permanent illness. Three of the main accounts will be explored here: (1) organophosphate induced delayed-polyneuropathy (OPIDP), (2) depleted uranium poisoning (DU) and (3) MCS.

\section{1. $O P I D P$}

The symptoms of GWS include various signs consistent with impaired CNS functioning, from sleep disturbance, affective and cognitive problems, to headaches and migraines, even blackouts and dizziness in some [16]. It has been argued that these symptoms can be explained by exposure to organophosphates (OPs) and anti-nerve agents [41]. Thus exposure to chemicals like pyridostigmine bromide (PB) and N, N-diethyl-m-toluamide (DEET) (both of which are neurotoxic) would be likely to produce long-term neurological changes [41] to basal ganglia and brain stem [44]. There is now a growing body of evidence to support this claim. Retrospective epidemiological data has shown a link between self reported levels of exposure to OPs and currently reported levels of symptoms [41]. More compelling biological evidence comes from two recent studies, one using magnetic resonance 
(MR) spectrosopy [44] and one examining genetic vulnerabilities (cf. [33,42]). The MR spectroscopy study showed neuronal damage in the basal ganglia and brain stem (5-20\% loss). The genetic study showed that ill veterans, and especially those scoring high on Haley et al.'s [38] neurological symptoms complex, were more likely than controls to have low levels of Paraoxonase (PON1) type Q arylesterase [42]. Paraoxonase is a high-density lipoprotein associated enzyme that hydrolyses arylesters and a variety of OPs and nerve agents (e.g., sarin). It follows that an inability to produce sufficient quantities of PON1 Q type would leave veterans particularly vulnerable to the effects of such agents (cf. [33]).

In the case of GWS, neurodegeneration through OP poisoning could have arisen through a variety of routes. First, PB has been found to interfere with controlled (apoptotic) brain cell death, both in vitro and (for up to 30 days) in an in vivo rat model [65]. Furthermore, although the entry of PB into the brain should be minimal, there is controlled experimental evidence that 'stress' (in the rat model induced by restraint and forced swim) can ease the passage of this potential neurotoxin across the blood-brain barrier [45], but see [103]. Also in an animal model, both experimental restraint stress and PB treatment can similarly increase startle responding, consistent with increased anxiety [100].

However, a number of problems have been raised with regard to OP poisoning as a complete account of GWS. First, there was no evidence of acute poisoning in the Gulf (see [29]). Second, a series of studies examining the effects of $\mathrm{PB}$ on neuromuscular junctions have shown the effects of PB to be reversible [22] and despite subjective reports of symptoms no pathology has been reported at the neuromuscular level [3]. Third, reported levels of PB exposure have recently been shown to be unrelated to handgrip strength [54]. Finally, a recent study has questioned the synergistic role of stress in relation to OPs passing the blood brain barrier [103].

Notwithstanding these issues the OPIDP model provides some partial account of GWS. However, whilst this theory can account for the persistence of (cognitive) symptoms (related to neurodegeneration), it cannot account for the breadth of symptoms, nor for their temporal variability.

\subsection{Depleted uranium}

Depleted uranium (DU) is a byproduct of the uranium enrichment process, expressing about $60 \%$ of the radioactivity of natural uranium (see $[71,84]$ ). It has been argued that exposure to DU particles during the Gulf War is another likely cause of veterans' current illness. A recent report examined the clinical effects of DU in 29 exposed (half with actual DU embedded shrapnel) and 38 non-exposed veterans [73]. A wide range of clinical (e.g., haematological analyses) and neurocognitive assessments (e.g., Wide Range Achievement Test 3, aspects of the Wechsler Adult Intelligence Test - Revised) were performed, with few significant differences shown between the groups. However, there was some evidence that elevated levels of uranium in the urine were associated with a reduction in neurocognitive function, suggesting that perhaps subtle health effects on neurocognition and reproductive health should be explored [73].

As well as these clinical data, the issue of levels of exposure (in terms of numbers affected and dosage) has to be considered. Not all veterans are likely to have encountered DU, in which case DU exposure cannot be a complete account of GWS.

\subsection{Multiple chemical sensitivity}

This occurs when individuals report a set of allergylike symptoms, when exposed to everyday volatile environmental agents (e.g., perfumes, glues, paint, cleaning fluids), at levels that most people find tolerable and unlikely to cause illness (see [64]). A number of explanations for MCS have been offered. Among the most extensively researched is an olfactory-limbic neural sensitization model (see [10]). This model suggests that repeated exposures to low levels of environmental toxins induce a process similar to neurological kindling that results in the limbic system becoming sensitized to low dosages of chemicals. In a similar vein, others have described a two-stage process of induction (sensitization) and triggering (generalization) similar to allergic illness [5]. Induction is usually via OPs or carbamates and triggering via generalization to a variety of other chemicals [5].

Bell and coworkers have produced an impressive body of biological and psychological data in support of the sensitization model (see [11-13]). Further support comes from animal models. For example, there are behavioural similarities between Flinder Sensitive Line rats and MCS patients [83] and experimental data showing that rats pre-exposed to formalin vapours demonstrated sensitization to a cocaine challenge [106].

An alternative, although not mutually incompatible, account of MCS is based on Pavlovian associative learning (see [19,102,119]). A series of experimental 
studies in humans have shown that an odour (e.g., ammonia: conditioned stimulus, CS), previously paired with illness induced by $\mathrm{CO}_{2}$ enriched air (unconditioned stimulus, UCS), will on later presentation elicit the same pattern of somatic symptoms (conditioned response, CR) as seen for $\mathrm{CO}_{2}$ (e.g., dizziness). This effect is known to generalize to other psychologically similar odours (e.g., other unpleasant but not pleasant odours) and to persist over long time durations [19]. However, the conditioning effect was most prominent for respiratory symptoms (e.g., fast breathing, tight chest), supporting the view that a Pavlovian mechanism might support the reporting of allergic type symptoms in particular contexts (e.g., [78]). On balance, it seems likely that the basic biological mechanism for MCS is likely to include sensitization, with Pavlovian conditioning providing a mechanism for generalization.

Does MCS offer a good account of GWS? On the face of it, it does in that it can account for the breadth of symptoms, their persistence and (in principle) their temporal variation. Epidemiological work has demonstrated that deployed veterans are twice as likely to meet the criteria for MCS than are non-deployed veterans (see [14]). However, a number of methodological problems have been identified with the reported literature on MCS and GWS [87]. Specifically, there are concerns about the following: (1) not all studies apply strict criteria for the presence of MCS, with some just assessing a more broadly defined general chemical intolerance (i.e. merely feeling ill when certain chemical smells are present does not necessarily reflect MCS), (2) co-morbidity factors are not assessed, (3) pre-war baseline data are not obtained, (4) not all studies have used reliable and valid assessment methods, and (5) appropriate comparison groups are not always used [87]. Furthermore, the sample sizes in the studies examining MCS in GWS vary from 41 through to 1000 s. The highest prevalence rate of $86 \%$ was reported for a study with 24 cases and 17 controls and assessed chemical intolerance rather than MCS (see also [75]). By contrast, larger epidemiological studies of Gulf war veterans, where systematic sampling error is likely to be reduced, report prevalence rates of less than $1 \%$ for chemical intolerance and 2-6\% for MCS (see [87]). On balance the evidence suggests that the prevalence rates among Gulf War veterans are too low to account for the number of veterans suffering from GWS. In fact the prevalence figures would be even lower if corrections for sensitivity and specificity in the measures were applied (cf. [38]).

\subsection{Summary of neurological accounts}

There is some evidence for CNS damage, at least in a small proportion of vulnerable veterans, which might be attributable to OP poisoning or neurological insult from DU exposure. In any case, whilst neurological damage on its own can account for the persistence of smaller set of cognitive impairments, it is an insufficient account of the breadth of symptoms seen in GWS, nor can it account for their variability. Similarly, the prevalence rates for MCS are not sufficient to account for the number of veterans reporting GWS.

\section{Immunological mechanisms}

Recent research associated with GWS has explored potential immunological accounts. Is the immune system of those with GWS in some way altered? In terms of basic immunological mechanisms some recent work has focused on the use of squalene as an adjuvant [4]. More psychoneuroimmunological accounts are discussed later.

\subsection{The squalene hypothesis}

Squalene is a non-steroidal precursor to cholesterol and produces a multi-system pattern of symptoms similar to that seen in GWS. Asa and coworkers [4] have demonstrated that (in their sample) all (or nearly all) Gulf War veterans who reported being ill (both deployed or not deployed) tested positive for anti-bodies to squalene. By contrast, not a single self-reported healthy Gulf War veteran tested positive for squalene. The argument is that those serving in the Gulf would have been vaccinated with squalene as an adjuvant, but this only really works if squalene administration can be shown to predict symptom levels. A further issue for the squalene account concerns the time interval for symptom onset. These authors reported that one of their positive controls (a National Institute of Health volunteer who received a squalene based adjuvant) became ill after three weeks [4]. However, the majority of veterans reporting GWS describe the onset of symptoms as being years rather than weeks after their return from the Persian Gulf. The issue of variable time delays between squalene administration and symptom onset needs to be addressed by any complete account of GWS. Finally, mild reactions for squalene in blood donors and CFS patients have also been reported [4]. 
These objections aside, since squalene can produce symptoms ranging from rashes and fatigue to headaches, this account has the potential to cover some of the breadth of symptoms reported in GWS, but not necessarily their persistence or any temporal variability.

\section{Behavioural mechanisms}

It has also been suggested that the experience and reporting of symptoms is mediated by basic Pavlovian mechanisms. Indeed, the work cited earlier in support of a Pavlovian account of MCS (see [19,102]) indicates that the experience of symptoms and their subsequent reporting can be learned and maintained behaviourally, especially in response to odour triggers.

Similarly, rats show 'bait shyness' even over long delays between the experience of food and illness, that typically result in complete avoidance of the food subsequently (making them very hard to poison). In human subjects, the extent of this phenomenon has been documented in a questionnaire study (of a sample of 517 undergraduates, $65 \%$ reported at least one aversion [66]). Such effects can be quite prolonged so that it requires a motivated effort to overcome initial nausea in order once more to be able to enjoy a particular food or drink. That is everyday experience would suggest that such reactions do not readily spontaneously disappear. However, the robustness of the effect is not necessarily due to a failure to extinguish in the conventional learning theoretic sense because the memory of illness can be sufficient to prevent subsequent exposure to the taste CS in question (and of course exposure is required for extinction to proceed). It follows, therefore, that limbic system structures involved in memory, may be implicated in this type of learning (see below).

In short, an associative mechanism based on flavour aversion could support the maintenance of symptom reporting and explain temporal variability (odour retriggering symptom reporting). However, without further elaboration, an associative account like this cannot account for the breadth of symptoms observed.

\section{Psychoneuroimmunological mechanisms}

Psychoneuroimmunological (PNI) accounts have focused on a role for cytokines in GWS. In particular, they have been based on (1) the relative balance between the Th1 (T-helper-1) and Th2 (T-helper-2) cytokine profiles [93] and (2) bio-associative processes involving IL-1 (see [29]). These models are discussed below, but it is first necessary to discuss the general functions of the cytokines and the Th1/Th2 profiles.

\subsection{Cytokines and the Th1-Th2 seesaw}

Two types of $\mathrm{T}$ helper (Th) response have been recognized in immunology: Th1 and Th2 (see [26,9092]). These two types of Th response are characterized by different patterns of cytokine activity. The Th1 response is mediated by the cytokines interleukin-2 (IL2 ), tumour necrosis factor beta (TNF- $\gamma$ ) and gamma interferon (INF- $\gamma)$. These Th1 cytokines stimulate natural killer (NK) cell and cytotoxic T lymphocyte (CTL) activity. They also activate macrophages and thus promote macrophage mediated inflammatory responses. The cytokine IL-1 is one of the main pro-inflammatory cytokines produced by macrophage activation. The Th1 profile is associated with fever, sickness behaviour, inflammatory responses and autoimmune diseases. The Th2 profile is characterized by the cytokines: IL-4, IL5, IL-6, IL-10 and IL-13. These stimulate antibody production, in particular immunoglobins $\mathrm{A}$ and $\mathrm{E}(\operatorname{Ig} \mathrm{A}$ and IgE). The Th2 cytokines also stimulate mast cell growth and eosinophil activation. Overactivity of the Th2 profile is associated with allergic illnesses such as asthma and Th2 activity can also produce inflammation via IgE. The Th1 and Th2 responses counter-regulate each other with INF- $\gamma$ inhibiting Th2 responses and IL-4 and IL-10 inhibiting Th1 responses. Finally, the distinction between Th1 and Th2 responses is very similar to the distinction between cellular immunity (Th1) and humoral immunity (Th2). However, although evidence tends to suggest that the Th1 and Th2 profiles are fairly distinct, there are a group of cells termed Th0 that can stimulate both Th1 and Th2 activity. Reviews of the distinction between Th1, Th2 and Th0-mediated responses can be found elsewhere [26,90-92].

\subsection{Th2 dominance hypothesis}

Rook and Zumla [93] have put forward a hypothesis that GWS (like CFS) is due to a shift in the Th1/Th2 balance towards a Th2 profile. They argue that 5 conditions present in the Gulf support this: (1) pertussis, a potential Th2 adjuvant, was used, (2) a large antigen load tends to produce Th2 dominance, (3) some of the vaccines used were Th2 inducing (e.g., anthrax, plague), (4) increased cortisol levels due to the stress of battle would favour a Th2 profile and (5) OPs inhibit IL-2 (a Th1 cytokine) driven activity. This account is categorized under PNI because it relies on stress (psychological), OPs (neurologically active) and immunology (Th1/Th2 profiles). 
While the argument in favor of a shift towards a Th2 profile is a convincing one, there are still a number of problems with this account. First, a Th2 profile tends to be associated with symptoms of allergic illness. There are reports that veterans show no higher incidence of allergic illness and symptoms than do controls (e.g. [32]). Second, three recent empirical studies have examined a variety of immunological factors (including cytokine profiles) in veterans' groups. One study found no evidence for a Th2 shift [104]. Others have demonstrated that (compared to controls) veterans with CFS showed a pattern of cytokine activity that was consistent with a Th1 rather than a Th2 profile [123]. By contrast, it has been shown that veterans with a diagnosis of PTSD $(N=3)$ were more likely to have reduced cellular (cf. Th1) immunity compared to veterans without a diagnosis of PTSD [27]. However, the Th2 dominance hypothesis relates primarily to CFS and GWS versus controls, so the Everson et al. [27] study does not make the appropriate comparison because they only used subgroups of veterans (with and without PTSD). Chronic stress shifts the immune system towards a Th2 profile (see [26]) and it is therefore not surprising that veterans with PTSD (i.e. under chronic stress) have a Th2 shift. Thus on balance, the current immunological evidence most clearly supports a shift in the cytokine balance towards a Th1 (rather than a Th2) profile in GWS [123]. But whilst immunological accounts such as this may be able to offer an explanation of the symptom diversity, they are less well equipped to explain symptom persistence.

\subsection{IL-1 and a bio-associative account}

One account that cuts across these different lines of investigation is Ferguson and Cassaday's [29] bioassociative model. This integrates psychological (stress), behavioural (Pavlovian conditioning), neurological (effects of stress and immunological parameters on the CNS) and immunological factors (an IL-1- based sickness response) into a single account of GWS.

The cytokine IL- 1 is pro-inflammatory and produces a spectrum of symptoms referred to as the 'sickness response' (fever, fatigue, memory and concentration problems, anorexia, sleep problems, sexual difficulties, depression, HPA activation, see $[6,46,58,69,70,117])$. Based on the high level of correspondence between the IL-1 induced sickness response and the symptoms seen in GWS, it has been suggested that the sickness response provides a likely basis for the spectrum of symptoms seen in GWS [29]. On this account, the various physiological (e.g., vaccines) and psychological (e.g., stress) challenges present in the Persian Gulf were sufficient to produce a (primary or unconditioned) sickness response [69]. It is further argued that the persistence of symptoms in GWS can be accounted for by Pavlovian bio-associative conditioning of the IL-1 sickness response to smells present in the Gulf (e.g., petroleum, oil fumes) that are also likely to be present in the home environment [29]. Once the sickness response (unconditioned response, UCR) has become associated with smells (CSs, e.g. petrol) that are present at the same time, later exposure to such CSs in the home environment will then produce the associated CR (the sickness response).

While similar in conceptualisation to the Pavlovian account of somatic illness described for MCS [19], this model provides a mechanism whereby environmental triggers could modulate immune responses [29]. However, although the model offers a PNI account of GWS, in that the detection of, and reaction to, environmental triggers will inevitably involve the CNS, such nonspecific symptoms are not 'psychologically-induced' in any conventional sense. Through classical conditioning, environmental triggers can have automatic effects on a range of biological systems. These effects are involuntary, typically occur without any conscious awareness and the physiological reactions so produced can be identical to those produced by the original challenge. In brief, the following kinds of evidence support the bio-associative account [29] outlined above: (1) the symptoms of the IL-1 induced sickness response show a high correspondence with the spectrum of symptoms seen in GWS (cf. [46]); (2) in general, there is good evidence that immune system parameters are conditionable [1]; (3) specifically, the neurological circuitry mediating IL-1 responses is conditionable and involved in taste aversion [34] with the bi-directional brain to immune system link mediated by the vagal nerve ([116], see [69] for a review); and (4) under experimental conditions, IL-1 can be used as a UCS to produce flavour aversion [34].

A number of pieces of recent evidence also lend support to this bio-associative account. First, there is now some evidence to support a Th1 shift in the cytokine profile of veterans with GWS (see [123]). IL-1 is produced primarily by macrophages and, although not a defining cytokine, is associated with the Th1 profile. Second, smells and taste, identified by veterans as present in the Persian Gulf, should be associated with current symptom levels. Consistent with this, it has been shown that (once levels of battlefield stress have 
been controlled for) retrospective recall of environmental exposures is significantly associated with current levels of reported physical symptom reporting [86]. For example, vehicle exhaust was associated with cardiac (e.g., chest pains) and neurological symptoms (e.g., headaches, numbness in limbs, dizziness). Similarly, smoke from tent heaters was associated with cardiac, neurological and pulmonary (e.g., shortness of breath, common cold or flu) symptoms. In addition, it has been shown that self reported war time environmental exposures (e.g., car exhaust, tent heaters etc.) predicted physical functioning in a sample of Gulf War veterans (fatigued versus non-fatigued) [31]. Others have found that current reports of severe GWS are associated with, amongst other things, retrospective reports of having come into contact with smoke or crude oil from oil well fires [80].

Such results mean that likely odour CSs (required by the bio-associative model of GWS [29]) are demonstrably related to symptom levels. It might be argued that these associations are equally supportive of an account of GWS based on MCS. However, as previously described, (see Multiple chemical sensitivity, above), the prevalence rate for MCS in veteran samples is not sufficient to account for the numbers reporting symptoms of GWS. Furthermore, the bio-associative model does not require, as an account based on MCS does, that these odours (the CSs) be the cause of GWS, merely that they become associated with the IL-1 sickness response. This matters because some of the odours mentioned (e.g., from car exhaust or tent heaters) are (in the absence of sensitization and/or associative effects) unlikely to cause illness. More importantly the odours identified were likely to have been experienced in the home environment before deployment in the Persian Gulf, so it is reasonable to assume that they were not already associated with feelings of illness. Evidently the physiological effects of such odours for some reason changed during service in the Persian Gulf and the bioassociative account would suggest that this change was due to associations being made with the IL-1 sickness response [29].

Finally, there is evidence that the experience of side effects from the vaccines used predicts current levels of symptom reporting [47]. Such side effects could be part of an IL-1 sickness response and as such would have contributed to the UCS required by the associative mechanism described by Ferguson and Cassaday [29].

\subsection{Summary of the PNI accounts}

The PNI accounts probably offer the most promising avenues to explain the patterns of symptom report- ing seen in GWS. Only further research will tell us whether a Th1 or a Th2 shift offers the best explanation of the underlying immunological processes. Irrespective of the direction of the underlying immune shift, the bio-associative effects could explain the breadth of symptoms in GWS, their persistence and temporal variability. Finally, they offer testable hypotheses, relate current symptoms to experiences in the Gulf and offer a plausible biological mechanism to account for the symptom diversity.

\section{Summary of explanations of GWS}

A variety of theories of GWS have been presented and the following conclusions can be drawn. First, there is limited evidence for neurological damage and this may be associated with OP poisoning. Second, psychiatric co-morbidity is present (particularly depression) but this can only account for a small proportion of the symptoms of GWS. Third, explanations based on PNI appear promising and make clear alternative predictions that are testable. For example, some suggest that there should be a Th2 shift [93] whereas others [29] suggest that there should be a Th1 shift. Finally, stress has a role in many of these models but its role is probably indirect. The implications of these issues are taken up below.

\section{Cytokines, IL-1, stress, the brain and neurological damage}

Based on the above review it is argued that cytokines and in particular IL-1 may have an important role to play in GWS. The biological basis for this would be that IL-1 produces a sickness response. Furthermore, it has been argued that 'stress' may have had a role to play initially as a co-factor in setting conditions that would make the veterans more vulnerable to biological challenges. This final section, therefore, reviews the current literature on the cytokines (in particular IL-1) and how in combination with stress these may influence long term disease and the onset of neurological disorders (e.g., Alzheimer's disease).

The role of psychological stress is included in many of the explanations of GWS described above. However, it is useful when considering stress to differentiate between acute and chronic stress. Whether or not the effects of stress on the immune system are suppressing or enhancing will depend on both the immune pa- 
rameter being studied and the type of stress (see [24, 26]). Evans and coworkers [26] suggest that acute stress may lead to an enhanced non-specific immune response (e.g., mediated by IL-6, which could lead to increased levels of IL-1) and potentially, increased levels of brain IL-1. Acute stress, in some species at least, may also make the blood-brain barrier more susceptible to these effects (cf. [45,103]). In addition, there is evidence that a single exposure to IL-1 can sensitize HPA axis activity by changes to the hypothalamic control of adrenocorticotropic hormone (ACTH) leading to an increased dominance of vasopressin secretion instead of corticotropin-releasing factor (CRF) [48,97, 98]. It has also been suggested that stress can prime delayed macrophage activity [69]. Thus stress could initiate increased levels of IL-1 (and the sickness response) and in turn IL-1 could sensitize the HPA axis (and again such effects would be exacerbated by a leaky blood-brain barrier).

Were soldiers in the Persian Gulf exposed to acute or chronic stress? In animal work an acute stressor is typically a short duration foot-shock or handling, whereas repeated administrations of foot-shock would be classified as chronic stress. In humans, cognitive appraisals are believed to underlie perceptions of stress [63] and as such the distinction between acute and chronic stress becomes blurred. The soldier in the Persian Gulf would be likely to have anticipated a number of possible negative events (seeing casualties, gas and scud attacks etc.) but may have experienced only one such event. In this case there would have been an acute stressor embedded within an ongoing background of chronic stressors. In humans, there is evidence that the experience of the acute stressor of taking an exam combined with the anticipation of approaching the exam can lead to a Th1 dominant cytokine response [68]. If (against a generally stressful background) the experience of an acute stressor can lead to a Th1 cytokine profile, with IL-1 potentially sensitizing the HPA axis, what further health implications would follow if such a system were self-sustaining and prolonged by Pavlovian associative processes?

There are cytokine receptors in a variety of brain regions and IL-1 in particular has been linked to neurodegenerative disease. For example, the IL-6 receptor is found, in the CA1-CA4 regions and the dentate gyrus of the hippocampus, the hypothalamus and the piriform cortex [99], whilst IL-1 seems to have the hypothalamus as its major site of action (see [95]). There is evidence that the cytokines exert diverse actions in the CNS and (in particular) they have been implicated in responses to disease and injury that have a neuronal component to their biological basis, providing a signalling method to and within the brain $[94,95]$. Thus, for example, whilst in the healthy brain (in the absence of inflammation), CNS IL-1 and IL-6 show controlled expression in response to peripheral immune challenges, in the diseased brain (after brain damage, e.g., due to OP poisoning), their synthesis is increased and this results in immune reactions, gliosis and neuronal growth [95,99]. As would be expected, cytokines also produce psychological effects. For example, in the rat, IL-1 inhibits long-term potentiation in the hippocampus and intracerebroventricular injections of IL-1 have been found to impair spatial navigation learning measured in the Morris water maze [82]. Similarly IL-1 has been implicated in a number of neurodegenerative diseases such as Alzheimer's disease, Parkinson's disease, multiple sclerosis, and epilepsy (see $[89,95,110])$. However, the exact causal nature of this relationship is yet to be established. IL-1 levels are also increased during depression [69] and in attempted suicide cases [77].

It follows that if an IL-1 response is involved in GWS, with reactivation and amplification through an associative mechanism, then long-term neurodegenerative diseases should show a higher prevalence in veterans with GWS. However, this conclusion must be seen as speculative as work establishing the causal role of IL-1 in neurodegenerative disease is at an early stage, as is work on the immunology of GWS.

\section{General conclusions}

It is argued that a PNI account of GWS based on a Pavlovian association of an IL-1 induced sickness response to smell may account for the breadth, persistence and variability of GWS and perhaps other functional syndromes. Future research needs to include more small scale theoretically driven studies, focusing on patterns in the report of symptoms, their environmental triggers and immunological correlates, with ERP and MRI scanning studies to examine neurological functioning and how this may change in response to immunological challenges.

Finally, the very brain structures that are damaged by stress (and, as we have seen, IL-1 can contribute to neurodegeneration) are part of the limbic system and this is implicated in the mediation of the bioassociative effects proposed to modulate nonspecific illness. For example, the neural circuitry for taste aversion is known to include both insular cortex and amygdala, and amyg- 
dala lesions can also disrupt the acquisition of conditioned immunosuppression [88]. However, we would not expect (for example) hippocampal damage necessarily to impair memory for the bioassociative triggers that activate the limbic system because the relevant associations may be non-declarative [20,23], consistent with the involuntary nature of such effects.

\section{References}

[1] R. Ader and N. Cohen, Psychoneuroimmunology: conditioning and stress, Annual Review of Psychology 44 (1993), 53-85.

[2] A. Amato, A. McVey, C. Cha, E. Matthews, C. Jackson, R. Kleingunther, L. Worlety, E. Cornman and K. Kagan-Hallet, Evaluation of neuromuscular symptoms in veterans of the Persian Gulf war, Neurology 48 (1997), 4-12.

[3] A. Andersen, J. Kiecolt-Glasser and R. Glasser, A biobehavioral model of cancer stress and disease course, American Psychologist 49 (1994), 389-404.

[4] P. Asa, Y. Cao and F. Garry, Antibodies to Squalene in Gulf War Syndrome, Experimental and Molecular Pathology 68 (2000), 55-64.

[5] N. Ashford and C. Miller, Chemical exposure: low levels and high stakes, Van Nostrand Reinhold, New York, 1991.

[6] R. Avitsur and R. Yirmiya, Cytokines inhibit sexual behaviour in female rats: 1 . synergistic effects of tumor necrosis factor $\alpha$ and interleukin-1, Brain, Behavior and Immunity 13 (1999), 14-32.

[7] D. Baker, C. Menddenhall, L. Simbartl, L. Magan and J. Steinberg, Archives of Internal Medicine 157 (1997), 20762078.

[8] A. Barksy and J. Borus, Functional somatic syndromes, Annals of Internal Medicine 13 (1999), 910-921.

[9] A. Baum and D. Posluszny, Health psychology: mapping biobehavioral contributions to health and illness, Annual Review of Psychology 50 (1999), 137-163.

[10] I. Bell, G. Schwartz, C. Baldwin, E. Hardin, N. Klimas, J. Kline, R. Patarca and Z. Song, Individual differences in neural sensitization and the role of context in illness from low-level environmental chemical exposures, Environmental Health Perspectives 105 (1997), 457-466.

[11] I. Bell, R. Bootzin, T. Davis, V. Hau, C. Ritenbaugh, K. Johnson and G. Schwartz, Time-dependent sensitization of plasma beta-endorphin in community elderly with self-reported environmental chemical odor intolerance, Biological Psychiatry 40 (1996), 134-143.

[12] I. Bell, G. Schwartz, E. Hardin, C. Baldwin and J. Kline, Differential resting quantitative electroencephalographic alpha in women with environmental chemical intolerance, depressives and normals, Biological Psychiatry 43 (1998), 376388.

[13] I. Bell, J. Wyatt, R. Bootzin and G. Schwartz, Slowed reaction time in performance on a divided attention task in elderly with environmental chemical odor intolerance, International Journal of Neuroscience 84 (1996), 127-134.

[14] D. Black, B. Doebbeling, M. Voelker, W. Clarke, R. Woolson, D. Barrett and D. Schwartz, Multiple chemical sensitivity syndrome: Symptoms prevalence and risk factors in a military population, Archives of Internal Medicine 160 (2000), 1169-1176.
[15] S. Cohen, D. Tyrrell and P. Smith, Negative life events, perceived stress, negative affect, and susceptibility to the common cold, Journal of Personality and Social Psychology 63 (1993), 131-140.

[16] W. Coker, B. Bhatt and J. Graham, Clinical findings for the first 1000 Gulf war veterans in the Ministry of Defence's medical assessment programme, British Medical Journal 318 (1999), 290-294.

[17] D. Cowan, G. Gray and R. DeFraites, Responding to inadequate critique of birth defects paper, American Journal of Epidemiology 148 (1998), 326-327.

[18] I. Deary, A taxonomy of medically unexplained symptoms, Journal of Psychosomatic Research 47 (1999), 51-59.

[19] S. Devriese, W. Winters, K. Stegen, I. Van Diest, H. Veulemans, B. Nemery, P. Eelen, K. Van de Woestijne and O. Van de Bergh, Generalization of acquired somatic symptoms in response to odors: A Pavlovian perspective on multiple chemical sensitivity, Psychosomatic Medicine 62 (2000), 751-759.

[20] A. Dickinson, Contemporary animal learning theory, Cambridge University Press, 1980.

[21] D. Doebbeling, W. Clarke, D. Watson, J. Torner, R. Woolson, M. Voelker, D. Barrett and D. Schwartz, Is there a Persian Gulf War Syndrome? Evidence from a large population based survey of veterans and nondeployed controls, American Journal of Medicine 108 (2000), 695-704.

[22] R. Drake-Baumann and F. Seil, Effects of exposure to low dose pyridostigmine on neuromuscular junctions in vitro, Muscle and Nerve 22 (1999), 696-703.

[23] H. Eichenbaum, T. Otto and N. Cohen, Two functional components of the hippocampal memory system, Behavioural and Brain Sciences 17 (1994), 449-518.

[24] I. Elenkov and G. Chrousos, Stress hormones, Th1/Th2 patterns, pro/anti-inflammatory cytokines and the susceptibility to disease, Trends in Endocrinology and Metabolism 10 (1999), 359-368.

[25] C. Engel, X. Liu, B. McCarthy, R. Miller and R. Ursano, Relationship of physical symptoms to posttraumatic stress disorder veterans seeking care for Gulf war-related health concerns, Psychosomatic Medicine 62 (2000), 739-745.

[26] P. Evans, F. Hucklebridge and A. Clow, Mind, immunity and health: the science of psychoneuroimmunology, Free Association Books, New York, 2000.

[27] M. Everson, S. Kotler and W. Blackburn, Stress and immunity dysfunction in Gulf war veterans, Annals of the New York Academy of Sciences 876 (1999), 413-418.

[28] E. Ferguson, Is there a Gulf War Syndrome? The Lancet 353 (1999), 1182.

[29] E. Ferguson and H. Cassaday, The Gulf war and illness by association, British Journal of Psychology 90 (1999), 459576.

[30] E. Ferguson, C. Lawrence and G. Matthews, Associations between primary appraisals and life events while controlling for depression, British Journal of Clinical Psychology 39 (2000), 143-155.

[31] N. Fiedler, G. Lange, L. Tiesky, J. DeLuca, T. Policastro, K. Kelly-McNeil, R. McWilliams, L. Korn and B. Natelson, Stressors, personality traits, and coping in Gulf war veterans with chronic fatigue, Journal of Psychosomatic Research 48 (2000), 525-535.

[32] K. Fukuda, R. Nisenbaum, G. Stewart, W. Thompson, L. Robin, R. Washko, D. Noah, D. Barrett, B. Randall, B. Herwaldt, A. Mawle and W. Eeeves, Chronic multi-system ill- 
ness affecting air force veterans of the Gulf War, Journal of the American Medical Association 280 (1998), 981-988.

[33] C. Furlong, PON1 status and neurologic symptom complexes in Gulf war veterans, Genome Research 10 (2000), 153-158.

[34] L. Goehler, C. Busch, N. Tartaglia, J. Relton, D. Sisk, S. Maier and L. Watkins, Blockade of cytokine induced conditioned taste aversion by subdiaphragmatic vagotomy: Further evidence for vagal mediation of immune-brain communication, Neuroscience Letters 185 (1995), 163-166.

[35] G. Gray, T. Smith, H. Kang and J. Knoke, Are Gulf war veterans suffering war-related illnesses? Federal and civilian hospitalizations examined, June 1991 to December 1994, American Journal of Epidemiology 151 (2000), 63-71.

[36] G. Gray, B. Coate, C. Anderson, H. Kanf, S. Berg, F. Wignall, J. Knoke and E. Barrerr-Connor, The postwar hospitalization experience of US veterans of the Persian Gulf war, New England Journal of Medicine 335 (1996), 1505-1513.

[37] G. Gray, J. Knoke, W. Berg, F. Wignall and E. BarrettConnor, Responding to suppositions and misunderstandings, American Journal of Epidemiology 148 (1998), 328-327.

[38] R. Haley, Is Gulf war syndrome due to stress? The evidence reexamined, American Journal of Epidemiology 146 (1997), 695-703.

[39] R. Haley, Bias from the 'healthy warrior effect' and unequal follow up in three government studies of health effects of the Gulf war, American Journal of Epidemiology 148 (1998), 315-323.

[40] R. Haley, Haley replies, American Journal of Epidemiology 148 (1998), 334-338

[41] R. Haley and T. Kurt, Self reported exposure to neurotoxic chemical combinations in the Gulf war, Journal of the American Medical Association 277 (1997), 2231-2237.

[42] R. Haley, S. Billecke and B. Du, Association of low PON1 Type Q (Type A) arylesterase activity with neurologic symptom complexes in Gulf war veterans, Toxicology and Applied Pharmacology 157 (1999), 227-233.

[43] R. Haley, T. Kurt and J. Hom, Is there a Gulf War Syndrome? Searching for syndromes by factor analysis of symptoms, Journal of the American Medical Association 227 (1997), 215-222.

[44] R. Haley, W. Marshall, G. McDonald, M. Daugherty, F. Petty and J. Fleckenstein, Brain abnormalities in Gulf War syndrome: Evaluation with H-1 MR spectroscopy, Radiology 215 (2000), 807-817.

[45] I. Hanin, The Gulf War, stress and a leaky blood-brain barrier, Nature Medicine 2 (1996), 1307-1308.

[46] B. Hart, Biological basis of behavior of sick animals, Neuroscience and Biobehavioral Reviews 12 (1988), 123-137.

[47] M. Hotopf, A. David, L. Hull, K. Ismail, C. Unwin and S. Wessley, Role of vaccinations as risk factors for ill health in veterans of the Gulf War: A cross sectional study, British Medical Journal 320 (2000), 1363-1367.

[48] I. Huitinga, E. Schmidt, M. van der Cammen, R. Binnekade and F. Tilders, Priming with interleukin- $1 \beta$ suppresses experimental allergic encephalomyelitis in the Lewis rat, Journal of Neuroendocrinology 12 (2000), 1186-1193.

[49] K. Hyams, S. Wignall and R. Roswell, War syndromes and their evaluation: From the US civil war to the Persian Gulf, Annals of Internal Medicine 125 (1996), 398-405.

[50] K. Hyams and R. Roswell, Resolving the Gulf war syndrome question, American Journal of Epidemiology 148 (1998), 339-342.

[51] T. Ishoy, P. Suadicani, M. Appleyard, H. Hein and F. Gyntelberg, State of health after deployment in the Persian Gulf:
The Danish Gulf War study, Danish Medical Bulletin 46 (1999), 416-419.

[52] K. Ismail, B. Everitt, N. Blatchley, L. Hull, C. Unwin, A. David and $\mathrm{S}$. Wessley, Is there a Gulf War syndrome? The Lancet 353 (1999), 179-182.

[53] S. Joseph, A comprehensive clinical evaluation of 20,000 Persian Gulf war veterans, Military Medicine 162 (1997), 149-155.

[54] K. Kaiser, A. Hawksworth and C. Gray, Pyridostigmine bromide intake during the Persian Gulf war is not associated with postwar handgrip strength, Military Medicine 165 (2000), $165-168$.

[55] H. Kang and T. Bullman, Mortality among US veterans of the Persian Gulf war, New England Journal of Medicine 335 (1996), 1498-1503.

[56] H. Kang and T. Bullman, Negligible 'healthy warrior effect' on Gulf war veterans' mortality, American Journal of Epidemiology 148 (1998), 324-325.

[57] M. Kemeny, F. Cohen, L. Zegans and M. Connat, Psychological and immunological predictors of genital herpes recurrence, Psychosomatic Medicine 51 (1989), 195-208.

[58] S. Kent, R. Bluthe, K. Kelley and R. Dantzer, Sickness behavior as a new target for drug development, Trends in the Pharmacological Sciences 13 (1992), 24-28.

[59] J. Kiecolt-Glasser, P. Marucha, W. Malarkey, A. Mercado and R. Glasser, Slowing of wound healing by psychological stress, The Lancet 346 (1995), 1194-1196.

[60] J. Kiecolt-Glasser, Stress, personal relationships, and immune function: Health implications, Brain, Behavior and Immunity 13 (1999), 61-72.

[61] J. Knoke, T. Smith, G. Gray, K. Kaiser and A. Hawksworth, Factor analysis of self-reported symptoms: Does it identify a Gulf War Syndrome? American Journal of Epidemiology 152 (2000), 379-388.

[62] G. Lange, L. Tiersky, J. DeLuca, A. Peckerman, C. Pollet, T. Policastro, J. Scharer, J. Ottenweller, N. Fiedler and B. Natelson, Psychiatric diagnosis in Gulf war veterans with fatiguing illness, Psychiatric Research 98 (1999), 39-48.

[63] R. Lazarus and S. Folkman, Stress, appraisals and coping, Verlag-Springer, New York, 1984.

[64] F. Levy, Clinical features of multiple chemical sensitivity, Scandinavian Journal of Work and Environmental Health $\mathbf{2 3}$ (1997), 69-73.

[65] L. Li, P. Gunasekar, J. Borowitz and G. Isom, Muscarinic receptor-mediated pyridostigmine-induced neuronal apoptosis, Neurotoxicology 21 (2000), 541-552.

[66] A. Logue, I. Ophir and K. Strauss, The acquisition of taste aversion in humans, Behavior Research and Therapy 19 (1981), 319-333.

[67] G. Macfarlane, E. Thomas and N. Cherry, Mortality among UK Gulf war veterans, British Medical Journal 356 (2000), 17-21.

[68] M. Maes, C. Song, A. Lin, R. De Jongh, A. Van Gastel, G. Kenis, E. Bosmans, I. De Meester, I. Benoy, H. Neels, P. Demedts, A. Janca, S. Scharpe and R. Smith, The effects of psychological stress on humans: increased production of pro-inflammatory cytokines and a Th1-like response in stress induced anxiety, Cytokine 10 (1998), 313-318.

[69] S. Maier and L. Watkins, Cytokines for psychologists: Implications of bi-directional immune-to-brain communication for understanding behavior, mood and cognition, Psychological Review 105 (1998), 83-107.

[70] S. Maier, L. Watkins and M. Fleshner, Psychoneuroimmunol- 
ogy: The interface between behavior, brain and immunity, American Psychologist 49 (1994), 1004-1017.

[71] J. Malone, B. Paige-Dobson, C. Ohl, C. DiGiovanni, S. Cunnion and M. Roy, Possibilities for unexplained chronic illness among reserve units deployed in operation desert shield/desert storm, Southern Medical Journal 89 (1996), 1147-1155.

[72] J. McCarroll, J. Fagan, J. Hermsen and R. Ursano, Posttraumatic stress disorder in US army Vietnam veterans who served in the Persian Gulf war, Journal of Nervous and Mental Diseases 185 (1997), 682-685.

[73] M. McDiarmid, J. Keogh, F. Hooper, K. McPhaul, K. Squibb, R. Kane, R. DiPino, M. Kabat, B. Kaup, L. Anderson, D. Hoover, L. Brown, M. Hamilton, D. Jacobson-Kram, B. Burrows and $\mathrm{M}$. Walsh, Health effects of depleted uranium on exposed Gulf war veterans, Environmental Research 82 (1999), $168-180$.

[74] B. McEwen, Stress and hippocampal plasticity, Annual Review of Neuroscience 22 (1999), 105-122.

[75] W. Meggs, Gulf war syndrome, chronic fatigue syndrome, and the multiple chemical sensitivity syndrome: Stirring the cauldron of confusion, Archives of Environmental Health 54 (1999), 309-311.

[76] O. Meijer, R.V. VanOoosten and E.R. DeKloet, Elevated basal trough levels of corticosterone suppress hippocampal 5-hydroxytyptamine (1A) receptor expression in adrenally intact rats: Implications for the pathogenesis of depression, Neuroscience 80 (1997), 419-426.

[77] S. Mendlovic, E. Mozes, E. Eilat, A. Doron, J. Lereya, V. Zakuth and Z. Spirer, Immune activation in non-treated suicidal major depression, Immunology Letters 67 (1999), 195-198.

[78] F. Michel, Psychology of the allergic patient, Allergy 49 (1994), 28-30.

[79] C. Morgan, S. Hill, P. Fox, P. Kingham and S. Southwick, Anniversary reactions in Gulf war veterans: A follow-up inquiry 6 years after the war, American Journal of Psychiatry 156 (1999), 1075-1079.

[80] R. Nisenbaum, D. Barrett, M. Reyer and W. Reeves, Deployment stressors and a chronic multisystem illness among Gulf war veterans, Journal of Nervous and Mental Diseases 188 (2000), 259-266.

[81] F. Ohl, T. Michaelis, G.K. Vollmann-Honsdorf, C. Kirschbaum and E. Fuchs, Effect of chronic psychosocial stress and long-term cortisol treatment on hippocampusmediated memory and hippocampal volume: A pilot study in tree shrews, Psychoneuroimmunology 25 (2000), 357-363.

[82] M. Oitzl, H. van Oers, B. Schobitz and E.R. de Kloet, Interleukin-1B, but not interleukin-6, impairs spatial navigation learning, Brain Research 613 (1993), 160-163.

[83] D. Overstreet, C. Miller, D. Janowsky and R. Russell, Potential animal model of multiple chemical sensitivity with cholinergic supersensitivity, Toxicology 111 (1996), 119134.

[84] Persian Gulf Veterans Coordinating Board, Unexplained illness among desert storm veterans: A search for causes, treatments and cooperation, Archives of Internal Medicine 115 (1995), 262-268.

[85] P. Pierce, Physical and emotional health of Gulf war veteran women, Aviation, Space and Environmental Medicine $\mathbf{6 8}$ (1997), 317-321.

[86] S. Proctor, T. Heeren, R. White, J. Wolfe, M. Borgos, J. Davis, L. Pepper, R. Clapp, P. Sutker, J. Vasterling and D. Ozonoff, Health status of Persian Gulf war veterans: Selfreported symptoms, environmental exposures and the effect of stress, International Journal of Epidemiology 27 (1998), 1000-1010.

[87] S. Proctor, Chemical sensitivity and Gulf war veterans' illnesses, Occupational Medicine: State of the art reviews $\mathbf{1 5}$ (2000), 587-599.

[88] V. Ramirez-Amaya, B. Alvarez-Borda and F. BermudezRattoni, Differential effects of NMDA-induced lesions into the insular cortex and amygdala on the acquisition and evocation of conditioned immunosuppression, Brain Behavior and Immunity 12 (1998), 149-160.

[89] E. Remarque, E. Bollen, A. Weverling-Rijnsburger, J. Laterveer, G. Blauw and R. Westendrop, Patients with Alzheimer's disease display a pro-inflammatory phenotype, Experimental Geronotology 36 (2000), 171-176.

[90] M. Rocken, M. Racke and E. Shevach, Il-4 induced immune deviation as antigen-specific therapy for inflammatory autoimmune disease, Immunology Today 17 (1996), 225-231.

[91] S. Romagnani, Induction of Th1 and Th2 responses: a key role for the natural immune response? Immunology Today 13 (1992), 379-381.

[92] S. Romangnani, The Th1/Th2 paradigm, Immunology Today 18 (1997), 263-266.

[93] G. Rook and A. Zumla, Gulf war syndrome: Is it due to a systematic shift in cytokine balance towards a Th2 profile? The Lancet 349 (1997), 1831-1833.

[94] N. Rothwell and S.J. Hopkins, Cytokines and the nervous system: 2. Actions and mechanisms of action, Trends in the Neurosciences 18 (1995), 130-136.

[95] N. Rothwell and G. Luheshi, Interleukin 1 in the brain: biology, pathology and therapeutic target, Trends in the Neurosciences 23 (2000), 618-625.

[96] M. Roy, P. Koslowe, K. Kroenke and C. Magruder, Signs, symptoms and ill-defined conditions in Persian Gulf War veterans: Findings from the comprehensive clinical evaluation program, Psychosomatic Medicine 60 (1998), 663-668.

[97] E. Schmidt, A. Janszen, F. Wouterlood and F. Tilders, Interleukin-1 induced long lasting changes in hypothalamic cortiotrophin releasing hormone (CRH) neurons and hyperresponsiveness of the hypothalamic-pituitary adrenal axis, Journal of Neuroscience 15 (1995), 7417-7426.

[98] E. Schmidt, R. Binnekade, A. Janszen and F. Tilders, Short stressor induced long-lasting increases of vasopressin stores in hypothalamic corticotrophin-releasing hormone (CRH) neurons in adult rats, Journal of Neuroendocrinology 8 (1996), 703-712.

[99] B. Schobitz, D.A.M. Voorhuis and E.R. De Kloet, Localization of interleukin 6 mRNA and interleukin 6 receptor mRNA in rat brain, Neuroscience Letters 136 (1992), 189-192.

[100] R. Servatius, J. Ottenweller, W. Guo, D. Beldowicz, G. Zhu and B. Natelson, Effects of inescapable stress and treatment with pyridostigmine bromide on plasma butyrylcholinesterase and the acoustic startle response in rats, Physiology and Behavior 69 (2000), 239-246.

[101] J. Sheridan, Stress-induced modulation of anti-viral immunity, Brain, Behavior and Immunity 12 (1998), 1-6.

[102] S. Siegel and R. Kreutzer, Pavlovian conditioning and multiple chemical sensitivity, Environmental Health Perspectives 105 (1997), 521-526.

[103] C. Sinton, T. Fitch, F. Petty and R. Haley, Stressful manipulations that elevate corticosterone reduce blood-brain barrier permeability to pyridostigmine in the rat, Toxicology and Applied Pharmacology 165 (2000), 99-105.

[104] P. Soetekouw, M. de Vries, F. Preijers, R. van Crevel, G. Bleijenberg and J. van der Meer, Persistent symptoms in for- 
mer UNTAC soldiers are not associated with a shifted cytokine balance, European Journal of Clinical Investigations 29 (1999), 960-963.

[105] P. Soetekouw, M. deVries, L. van Bergen, J. Galama, A. Keyser, G. Blieijenberg and J. van der Meer, Somatic hypotheses of war syndromes, European Journal of Clinical Investigations 30 (2000), 630-641.

[106] B. Sorg, J. Willis, T. Nowatka, C. Ulibarri, R. See and H. Westberg, Proposed animal neurosensitization model of multiple chemical sensitivity in studies with formalin, Toxicology 111 (1996), 135-145.

[107] L. Squire, Memory and the hippocampus: a synthesis from findings with rats, monkeys, and humans, Psychological Review 99 (1992), 195-231.

[108] D. Storzbach, K. Campbell, L. Binder, L. McCauley, W. Anger, D. Roclman and C. Kovera, Psychological differences between veterans with and without Gulf war unexplained symptoms, Psychosomatic Medicine 62 (2000), 726-735.

[109] R. Stretch, P. Bliese, D. Marlowe, K. Wright, K. Knudson and C. Hoover, Psychological health of Gulf war-era military personnel, Military Medicine 161 (1996), 257-261.

[110] K. Tha, Y. Okuma, H. Miyazaki, T. Murayama, T. Uehara, R. Hatakeyama, Y. Hayashi and Y. Nomura, Changes in expression of proinflammatory cytokines IL- $1 \beta$, TNF- $\alpha$ and IL-6 in the brain of senescene accelerated mouse (SAM) P8, Brain Research 885 (2000), 25-31.

[111] R. Toomey, S. Faraone, J. Simpson and M. Tsuang, Negative, positive, and disorganized symptom dimensions in schizophrenia, major depression, and bi-polar disorder, Journal of Nervous and Mental Disease 186 (1998), 470-476.

[112] R. Toomey, W. Kremen, J. Simpson, J. Samson, L. Seidman, M. Lyons, S. Faraone and M. Tsuang, Revisiting the factor structure of positive and negative symptoms: Evidence from a large heterogeneous group of psychiatric patients, American Journal of Psychiatry 154 (1997), 371-377.

[113] C. Unwin, N. Blatchley, W. Coker, S. Ferry, M. Hotopf, L. Hull, K. Ismail, I. Palmer, A. David and S. Wessley, Health of UK servicemen who served in the Persian Gulf war, The Lancet 353 (1999), 169-178.

[114] A. Van Haarst, M. Oitzl and E. De Kloet, Facilitation of feedback inhibition through blockade of glucocorticoid receptors in the hippocampus, Neurochemical Research 22 (1997), 1323-1328.

[115] K. Vedhara, J. Hyde, I. Gilchrist, M. Tytherleigh and S. Plummer, Acute stress, memory, attention and cortisol, Psychoneuroendocrinology 25 (2000), 535-549.

[116] L. Watkins, L. Goehler, J. Relton, N. Tartaglia, L. Silbert, D. Martin and S. Maier, Blockade of interleukin-1 induced fever by subdiaphragmatic vagotomy: Evidence for vagal mediation of immune-brain communication, Neuroscience Letters 183 (1994), 1-5.

[117] L. Watkins and S. Maier, The pain of being sick: implications of immune-to-brain communication for understanding pain, Annual Review of Psychology 51 (2000), 29-57.

[118] D. Wegman, N. Woods and J. Ballar, How would we know a Gulf war syndrome if we saw one? American Journal of Epidemiology 146 (1997), 704-711.

[119] B. Weiss, Neurobehavioral properties of chemical sensitivity syndromes, Neurotoxicology 19 (1998), 259-268.

[120] S. Wessley, C. Nimnuan and M. Sharpe, Functional somatic syndromes: one or many? The Lancet 354 (1999), 936-939.

[121] J. Wolfe, S. Proctor, D. Erikson, T. Heeren, M. Friedman, M. Huang, P. Sutker, J. Vasterling and R. White, Relationship of psychiatric status to Gulf war veterans' health problems, Psychosomatic Medicine 61 (1999), 532-540.

[122] J. Wolfe, D. Erickson, E. Sharkansky, D. King and L. King, Course and predictors of post-traumatic stress disorder among Gulf war veterans: A prospective analysis, Journal of Consulting and Clinical Psychology 67 (1999), 520-528.

[123] Q. Zhang, X. Zhou, T. Denny, J. Ottenweller, G. Lange, J. LaManca, M. Lavietes, C. Pollet, W. Gause and B. Natelson, Changes in immune parameters seen in Gulf War veterans but not in civilians with chronic fatigue syndrome, Clinical Diagnostic Laboratories and Immunology 6 (1999), 6-13. 


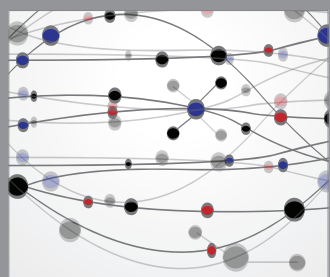

The Scientific World Journal
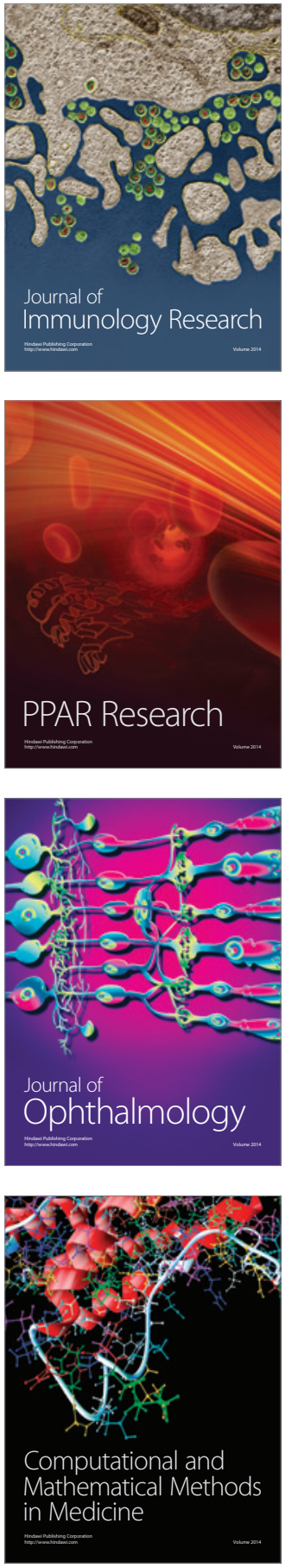

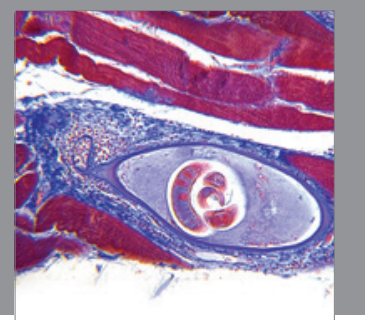

Gastroenterology

Research and Practice
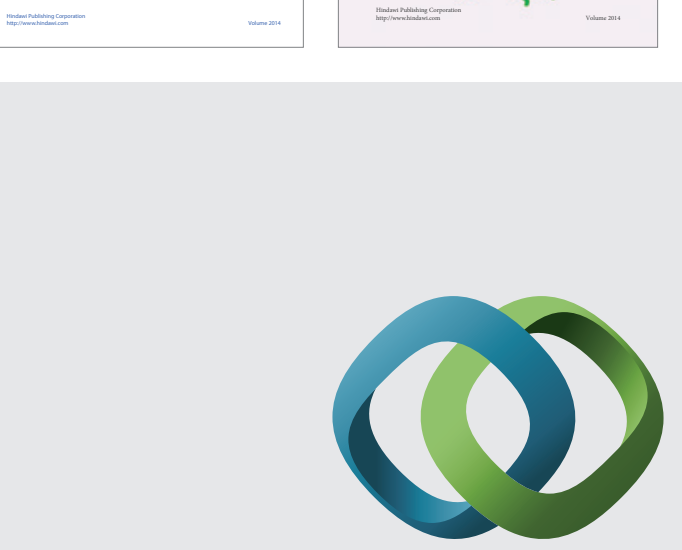

\section{Hindawi}

Submit your manuscripts at

http://www.hindawi.com
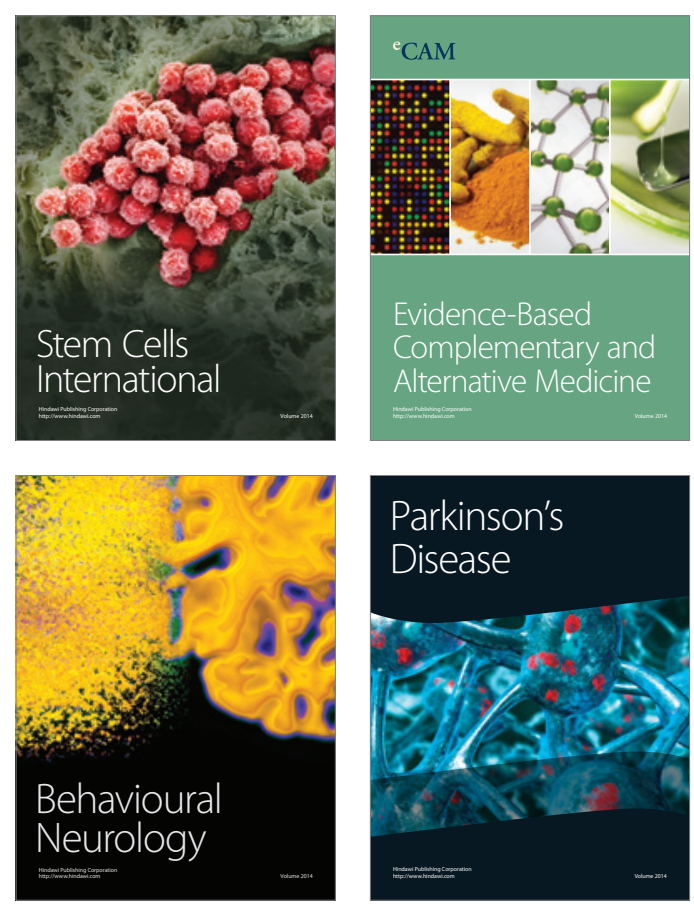

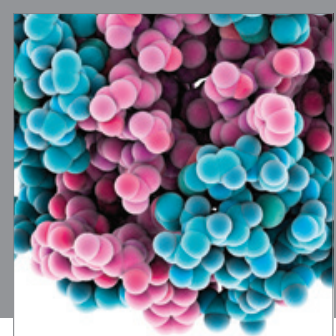

Journal of
Diabetes Research

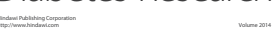

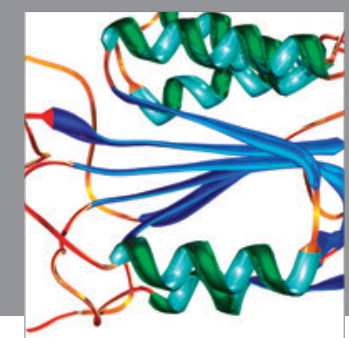

Disease Markers
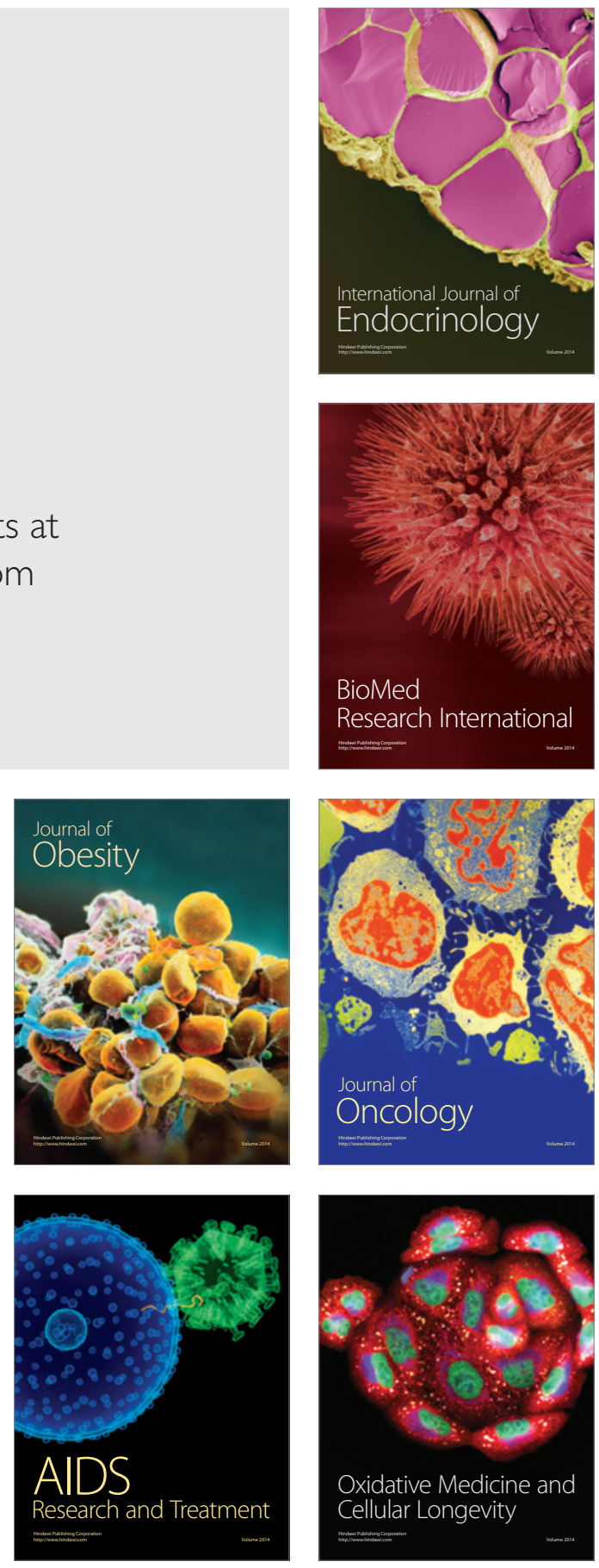